This item was submitted to Loughborough's Research Repository by the author.

Items in Figshare are protected by copyright, with all rights reserved, unless otherwise indicated.

\title{
A systematic review of the intrapersonal correlates of motivational climate perceptions in sport and physical activity
}

PLEASE CITE THE PUBLISHED VERSION

http://dx.doi.org/10.1016/j.psychsport.2014.11.005

\section{PUBLISHER}

(C) Elsevier Ltd

\section{VERSION}

AM (Accepted Manuscript)

\section{PUBLISHER STATEMENT}

This work is made available according to the conditions of the Creative Commons Attribution-NonCommercialNoDerivatives 4.0 International (CC BY-NC-ND 4.0) licence. Full details of this licence are available at: https://creativecommons.org/licenses/by-nc-nd/4.0/

\section{LICENCE}

CC BY-NC-ND 4.0

\section{REPOSITORY RECORD}

Harwood, Chris, Richard J. Keegan, Jonathan M.J. Smith, and Adam S. Raine. 2014. "A Systematic Review of the Intrapersonal Correlates of Motivational Climate Perceptions in Sport and Physical Activity”. Loughborough University. https://hdl.handle.net/2134/17020. 
INTRAPERSONAL CORRELATES OF MOTIVATIONAL CLIMATES

1 RUNNING HEAD: Intrapersonal Correlates of Motivational Climates

2

3

4

5

6

7

8

9

10

6

21

A Systematic Review of the Intrapersonal Correlates of Motivational Climate Perceptions in Sport and Physical Activity

(7)

8

9

20 
INTRAPERSONAL CORRELATES OF MOTIVATIONAL CLIMATES

2 Objectives: The purpose of this study was to systematically review and appraise the achievement goal literature (1990-2014) with a view to identifying the intra-individual correlates of motivational climate perceptions, and to identify research gaps and avenues in need for further development. Method: Four databases were searched, leading to 104 published studies being sampled (121 independent samples) that met inclusion criteria. Correlates were grouped into 17 categories and qualitative analysis focussed on identifying the associations predicted by achievement goal theory. Effect sizes were calculated using the Hunter-Schmidt method for correcting sampling error. Results: A total population size of $34,156(\chi=316.3, \sigma=268.1)$ was sampled in the analysis, with the published mean ages ranging from 10.0 to 38.2 years $(\chi=16.5$ years, $\sigma=4.7)$. Perceptions of a task or mastery climate were consistently associated with a range of adaptive motivational outcomes including perceived competence, self-esteem, objective performance, intrinsic forms of motivational regulation, affective states, practice and competitive strategies and moral attitudes, and the experience of flow. Perceptions of an ego or performance climate were positively associated with extrinsic regulation and amotivation, negative affect, maladaptive strategy use, antisocial moral attitudes and perfectionism, but negatively associated to positive affect and feelings of autonomy and relatedness. Conclusions: After reviewing the sum total of research in this topic area, the authors appraise the options for future research to make meaningful progress in developing understanding of the social determination of motivation in sport and physical activity settings.

Keywords: achievement goals, correlates, motivational climate, coach, parents, peers

Funding statement: This study did not receive any funding and there are no conflicts of interests to declare. 
INTRAPERSONAL CORRELATES OF MOTIVATIONAL CLIMATES

\section{A Systematic Review of the Intrapersonal Correlates of Motivational Climate Perceptions in Sport and Physical Activity}

Over the past 30 years, research on achievement motivation within sport and physical activity domains has received unprecedented attention, generating an extensive range of publications. In developing Achievement Goal Theory (AGT), Nicholls $(1984,1989)$ proposed that in achievement contexts the meaning of competence to any individual could be defined as follows:

Achievement behaviour is defined as behaviour directed at developing or demonstrating high rather than low competence. It is shown that competence can be conceived in two ways. First, ability can be judged high or low with reference to the individual's own past performance or knowledge [termed task goals]. In this context, gains in mastery indicate competence. Second, ability can be judged as capacity relative to that of others [termed ego goals]. In this context, a gain in mastery alone does not indicate high competence. To demonstrate high capacity, one must achieve more with equal effort, or use less effort than do others for an equal performance. (Nicholls, 1984; p. 328 - italics added)

In subsequent research, these two definitions of competence have been applied at different levels of analysis: (a) the state level (goal involvement); (b) the situational/contextual level (climate); and (c) the dispositional level (goal orientation). Within AGT, participants' immediate goals for achievement (a) are determined by the interaction between (c) their goal orientation (a proneness in individuals towards adopting certain goals; cf. Duda, 1993) and (b) the situational goal climate (defined as the specific situational and contextual circumstances in which the achievement task is defined; cf. Ames, 1992a). Ames (1992b) asserted that the individual's subjective perception of the motivational environment was the critical factor in predicting subsequent psychological and behavioural responses. These developments led researchers to define two types of motivational climate: a 'mastery' climate reflecting task goals, and a 
INTRAPERSONAL CORRELATES OF MOTIVATIONAL CLIMATES

1 'performance' climate endorsing ego goals (Blumenfeld, 1992).

Notionally, any individual participating in sport and physical activity settings can influence the motivational climate by differentially emphasising task-mastery or ego-performance goals; through their visible attitudes and behaviours. In attempts to quantitatively capture such social behaviour and its effects, several questionnaires have been developed to assess the perceived influences of teachers, coaches, parents and peers separately. Following Ames' (1992b) assertion that the subjective perceptions of the motivational environment were critical, these questionnaires focussed on the perceived situational and contextual goal emphases in sport and physical education settings. These questionnaires included: (1) teacher focussed scales, such as the Learning and Performance Orientations in Physical Education Classes Questionnaire (LAPOPECQ - Papaioannou, 1994; 1995; 1997), and its abridged version the Teacher-Initiated Motivational Climate Questionnaire (Papaioannou, 1998). Likewise, the Physical Education Class Climate Scale (PECCS - Goudas \& Biddle, 1994), and L'Echelle de Perception du Climat Motivational (EPCM - Biddle, Cury, Goudas, Sarrazin, Famose, \& Durand, 1995); (2) coach focussed inventories, such as the Perceived Motivational Climate in Sport Questionnaire (PMCSQ - Seifriz, Duda \& Chi, 1992), PMCSQ-2 (Newton \& Duda, 1993) and the Motivational Climate Scale for Youth Sports (MCSYS - Smith, Cumming \& Smoll, 2008); (3) parent focussed measures, such as the Parent Initiated Motivational Climate Questionnaire (PIMCQ-2 - White, 1996); and (4) peer-focussed instruments, such as the Peer Motivational Climate in Youth Sport Questionnaire (PeerMCYSQ - Ntoumanis \& Vazou, 2005). Many of these questionnaires, their strengths, weaknesses and associated findings are reviewed in Harwood, Spray and Keegan (2008) and Duda and Whitehead (1998). However, in succinctly summarising the sub-factors of these scales: (i) effort, (ii) learning/skill-improvement, (iii) perceived important role, (iv) cooperative learning and (v) 'mistakes-are-part-of-learning' are key themes of Perceived Task/Mastery Climate questionnaire items (hereafter PTMC). In contrast, subscales which assess: (i) interpersonal comparison (and rivalry); (ii) punishment/fear of mistakes; (iii) unequal 
INTRAPERSONAL CORRELATES OF MOTIVATIONAL CLIMATES

1 treatment of players; and (iv) 'achieving-without-effort' are consistent themes of Perceived

2 Ego/Performance Climate questionnaire items (hereafter PEPC).

A great deal of research has focused upon the antecedents and consequences of athletes' task and ego orientations as dispositional achievement tendencies in sport (see Biddle, Wang,

5 Chatzisarantis \& Spray, 2003 for a systematic review, and Van Yperen, Blaga \& Postmes, 2014

6 for a meta-analysis). This investment in goal orientation research has been paralleled by an

7 ongoing academic interest in perceived motivational climate. An abundance of research has

8 investigated the motivational, affective and behavioural correlates of PTMCs and PEPCs. In the

9 first narrative review of the area, Ntoumanis and Biddle (1999) appraised attempts to

10 experimentally manipulate motivational climate, and included a brief analysis of the correlates of

11 climate perceptions. Nine years later, Harwood et al. (2008) completed a qualitative review of the theoretical associations between perceived motivational climate and outcomes such as perceived competence, positive- and negative-affective states, beliefs about the purpose of sport (status versus development) and also the causes of success in sport (effort/learning versus natural ability).

In both analyses, the same pattern was reported wherein PTMCs were associated with motivational climate has contributed very meaningfully to our understanding of how these perceptions are associated to psychosocial functioning in sport and physical activity settings. On the other hand, findings can often be equivocal or inconsistent between studies, and the broad pattern of associations has not been comprehensively, systematically, recorded at this time. As such, there is a strong argument for conducting a systematic review of the correlates of perceived motivational climate. Further, with research tending to focus on the meaning of achievement contexts to the individual (as noted above), a review focussing on the intrapersonal correlates of perceived motivational climate appears timely. 
INTRAPERSONAL CORRELATES OF MOTIVATIONAL CLIMATES

Systematic reviews aim to identify, evaluate and summarise the findings of all relevant individual studies, thereby making the available evidence more accessible (Higgins \& Green, 2011). When appropriate, combining the results of several studies gives a more reliable estimate of an intervention's effectiveness than one study alone (Murtagh et al., 2007; Pope \& Mays, 2006; Roen, Aray, Roberts \& Popay, 2006). Systematic reviews adhere to a strict scientific design based on transparent, pre-specified and reproducible methods and all the data they employ is publically available for others to inspect (Higgins \& Green, 2011). Because of this rigour, when carried out well, systematic reviews provide reliable summaries of the current state-of-theliterature, thus rendering any conclusions more defensible. As well as setting out what we know about a particular topic, systematic reviews can also demonstrate where knowledge is lacking (Giacomini \& Cook, 2000; Dixon-Woods et al., 2006), which can then be used to inform future research (Pawson, Greenhalgh, Harvey \& Walsh, 2004). Further, systematic reviews can be differentiated from meta-analyses, which seek to use quantitative methods to summarise overall effect sizes and trends. For example, a systematic review can be purely qualitative if insufficient quantitative data exist. However, where appropriate, systematic reviews can be informed by metaanalytic techniques (Alderson \& Green, 2008), as is the case in the present study.

With an ever-growing body of research using correlational designs to explore the associations of motivational climate perceptions in sport and physical activity, this systematic review was undertaken with three objectives. First, to uncover and examine the known intrapersonal correlates of the achievement goals construct: perceived motivational climate. Second, to capture and record the theoretical explanations for such correlations. Third, to summarise the findings of published correlational studies within the sampling period January 1990 - January 2014. Likewise, this study set out to evaluate the value of correlational research in examining the social and cognitive processes influencing motivation in sport and physical activity - both to date and looking forwards to the future. From this robust platform, conclusions and recommendations can subsequently be made relating to perceived limitations in current 
INTRAPERSONAL CORRELATES OF MOTIVATIONAL CLIMATES

1 knowledge and directions for future studies.

\section{Method}

Search Strategy

Published studies were selected for the systematic review through electronic searches of

four computer databases that were either sport specific (SPORTdiscus), psychology specific (PsycINFO) or general (Web of Science and PubMed) - see Figure 1 for PRISMA diagram. To assist with replication efforts, Google Scholar was not included as a database following the establishment of inclusion criteria (c), below. This database did not offer any additional findings and generated a substantial time cost from processing papers that did not meet the inclusion criteria (cf. Higgins \& Green, 2011). Further, additional searches were conducted by reviewing article reference lists and the authors' personal archives. Key word combinations to locate studies were based around the following Boolean search term: "(sport OR physical education OR physical activity OR exercis*) AND (motivational climate) AND (correl* OR relat* OR assoc*), which was developed through critical discussions between the authors.

\section{Eligibility Criteria}

Inclusion/exclusion criteria were employed to ensure that the boundaries of the review were clearly defined, and that the search strategy would identify all literature relevant to the aims of the review (CRD, 2009; Smith, 2010). The following inclusion and exclusion criteria were deployed in this study, with criteria a-c being applied during the search process, by using the advanced search options within the chosen databases: (a) papers must be published in the English language between January 1990 and January 2014; (b) papers must be original articles, and not dissertations, books, theses or conference proceedings; (c) with a view to creating a manageable sample size (i.e., approx. 100 - cf. CRD, 2009), papers must be published in a peer reviewed journal with an impact factor; (d) full text article available; (e) correlations must be between perceived motivational climate and intrapersonal variables (i.e., cognitive, affective and behavioural variables - cf. Dixon-Woods \& Fitzpatrick, 2001; Morgan \& Carpenter, 2002); (f) 
INTRAPERSONAL CORRELATES OF MOTIVATIONAL CLIMATES

1 papers must report the raw correlation values between perceptions of motivational climate and the associated correlate(s); (g) papers must pertain to populations from sport, physical activity or physical education, but not other areas such as the workplace or academic classroom; (h) papers must have gathered original empirical data; and (i) special populations such as those with mental illness, psychiatric disorders, developmental delays and developmental co-ordination or eating disorders, were excluded. Finally, on the grounds that three or more comparisons are necessary to generate a meaningful summary (cf. Sallis et al., 2000), categories with fewer than three independent samples were not subjected to quantitative analysis. For the application of these criteria, three members of the research team reviewed all of the included papers separately, and the second author also reviewed a sample of the papers rejected by colleagues. Where any queries were raised, the analysts reviewed the paper together and applied the above criteria, making a decision and recording the reasons for any rejections. There was good agreement in the first instance, with discrepancies due to papers, upon closer examination, failing to report the raw correlations between climate perceptions and the associated variable(s).

\section{Data Extraction}

The extracted data included: (a) authors; (b) country in which the study was conducted; (c) sample characteristics (number/size, age, and gender); (d) questionnaires deployed to assess the perceived motivational climate; (e) the reliability of climate perceptions measurement (Cronbach's alpha); (f) the reliability of the associated correlates (either Cronbach's alpha or testretest for non-questionnaire data); and (g) year of publication. When details of mean age were not available, an average was calculated from the age range provided. If a study reported multiple analyses on correlates (i.e., longitudinal studies), priority was given to the measurement of the correlate that took place closest, chronologically, to the measurement of climate perceptions.

Where relevant measures were taken at multiple time points, the first data-collection was used (i.e., prior to any intervention). Where studies did not report the reliability of their measures, data was inputted either from the original validation paper or, failing that (for example, where the 
INTRAPERSONAL CORRELATES OF MOTIVATIONAL CLIMATES

1 original validation was in another language), a more recent paper including reliability data. Where single item measures or unique one-off measures were used, 0.70 was inputted as a conservative yet acceptable measure of reliability (cf. Cohen \& Cohen, 1983). The full table of extracted data and a completed PRISMA 2009 checklist are available online in Supplementary Tables 1 and 2. Analysis

Quantitative analysis. We used the analytical procedures proposed by Hunter and Schmidt (2004) to correct for sampling and measurement errors. This method adopts a randomeffects model, which allows population effect sizes to vary across studies and provides estimates of these variations. For each effect size, an estimate of the true population correlation $(\rho)$ was calculated. Using the criteria suggested by Cohen (1977), correlations above 0.50 are considered large; those between 0.30 and 0.50 are considered moderate; and those between 0.10 and 0.30 are considered small. The $95 \%$ confidence interval (CI) of each estimate was constructed around the true score correlation. If a CI encompassed zero, then we determined that there was no relation between the two constructs. We calculated total variances of the correlations, as well as those attributed only to sampling and measurement errors. Consistent with the recommendations of Hunter and Schmidt (2004), effect sizes were considered homogenous if $75 \%$ or more of the total variances were attributed to corrected artefacts (i.e., sampling and measurement errors). Failure to reach this criterion would imply moderation by such factors as study design (sample size or type, measures used) or even other variables - for example the effect of perceived motivational climate on affective states is proposed to be moderated by the individual's goal orientation (Wang, Liu, Chatzisarantis, \& Lim, 2010).

Qualitative analysis. Once the final 104 studies had been identified, the relevant sections in each were repeatedly read by the second author, an experienced qualitative analyst, in order to become familiar with, and immersed in, the data to fully appreciate its significance (see Maykut \& Morehouse's [1994] concept of indwelling). In the first instance, as correlations were sampled and recorded, the analyst coded them into semantically similar categories - for example clustering 
INTRAPERSONAL CORRELATES OF MOTIVATIONAL CLIMATES

1 enjoyment, satisfaction and interest under 'positive affect'. Secondly, theoretical explanations were developed to explain linkages between each perceived climate (PTMC and PEPC) and the coded correlate categories. Thirdly, trends and patterns in the presentation and interpretation of findings were recorded and reviewed, with a view to informing the critical discussion and recommendations to accompany the main results (presented in the Discussion section).

\section{Results}

\section{General Results}

Table 1 provides a summary of the sampling characteristics across the studies, including 121 independent samples (104 articles - See Table 1) with a total population size of $34,156(\chi=$ $316.26, \sigma=268.07)$. Papers reported an average of 6.5 correlations each, between climate perceptions and related variables. The published mean ages ranged from 10.0 to 38.2 years $(\chi=$ 16.46 years, $\sigma=4.73$ ) with $77.8 \%$ of those sample means being under the age of 20 years (absolute upper to lower limits were 9 years to 64 years, respectively). In total, 14,109 (41.3\%) participants were female, 18,051 (52.6\%) were male, and for 1,996 participants (5.8\%) gender was not specified.

Of the 104 studies, the majority were from the USA $(k=33,31.7 \%)$, UK $(k=17,16.4 \%)$, Spain $(k=13,12.5 \%)$, and Norway $(k=11,10.6 \%)$, with the remainder being drawn from Canada (3), Estonia (2), Finland (3), France (4), Greece (5), Italy (4), Japan (1), the Netherlands (1), Poland (1), Singapore (3), South Korea (2), and one cross national study (Kristiansen, Roberts \& Abrahamsen, 2008). Motivational climate has been studied in a range of physical activity contexts: the largest proportions representing participants in $\mathrm{PE}(k=34,32.7 \%)$, and in team sports $(k=34,32.7 \%)$. Only $12.5 \%(k=13)$ of the articles sampled exclusively from participants in individual sports, and $15.4 \%(k=16)$ recruited from both team and individual sports. Five studies (4.8\%) pertained to exercise classes, two were drawn from dance classes, and one employed a motor skill acquisition task (Hogue, Fry, Fry \& Pressman, 2013). Finally, to assess the perceived motivational climate, the majority of studies either used the PMCSQ-2 $(k=$ 
INTRAPERSONAL CORRELATES OF MOTIVATIONAL CLIMATES

$140,38.5 \%)$ or the PMCSQ $(k=24,23.1 \%)$ with the LAPOPECQ $(k=8,7.7 \%)$, PECCS $(k=5)$,

2 PeerMCYSQ $(k=5)$ and PIMCQ-2, EPCM and TIMCQ (all $k=3$ ) being selectively employed.

\section{Summary of Correlates of Perceived Motivational Climate}

Seventeen categories emerged to describe the intrapersonal correlates of perceived

motivational climate (See Tables 2 and 3). For ease of presentation, these categories have been distilled into six higher order themes deemed representative of each category. In these six subsequent thematic sections, each category of correlates is explained, its theoretical links are specified, and the quantitative findings are reviewed.

Goal orientations and adoptions. Individual differences in goal orientation or goal adoption emerged as an extensively studied correlate of PMC. Theoretical and empirical literature generally predicts that there should be positive associations between a PTMC and task orientation, and also PEPC and ego-orientation. There are no clear theoretical reasons to posit correlations between PTMC and ego-orientation or PEPC and task-orientation. Mechanisms may include the 'socialisation' effect of climates influencing goal-orientation, the 'gravitation' of athletes with a particular achievement goal towards activities where that climate prevails, or goal orientations may cognitively bias the athlete's perception of the motivational climate (cf. Harwood et al., 2008).

In relation to task orientations, 67 correlations were sampled, with a total population of 20,302 $(\chi=303.1)$. Overall there was a moderate positive effect size between PTMC and taskorientation $(\rho c=0.46, C I=0.42-0.51)$, with acceptable homogeneity of variance. In contrast, there was no notable association between PEPC and task-orientation (see Table 3). In relation to ego-orientation, 61 correlations were sampled, with a total population of $17,789(\chi=291.6)$. There was a moderate positive association between PEPC and ego-orientation $\left(\rho_{\mathrm{c}}=0.36, \mathrm{CI}=\right.$ 0.32-0.39), but no association between PTMC and ego-orientation (see Table 2). Elliot and colleagues expanded the dichotomous model of achievement goals, by proposing the bifurcation of ego/performance goals into performance-approach (PApp) and 
INTRAPERSONAL CORRELATES OF MOTIVATIONAL CLIMATES

1 performance-avoidance (PAv) goals (Elliot \& Church, 1997). This was closely followed by the

2 division of mastery goals into mastery-approach (MApp) and mastery-avoidance (MAv - Elliot \&

3 McGregor, 2001). Several studies have also correlated perceptions of the motivational climate with these more recent forms of goal adoption (NB: not conceptualised as dispositions, as with goal orientation - cf. Elliot, 1999). Five samples, totalling 1,345 participants $(\chi=269.00)$, correlated climate perceptions with MApp and MAv goals, whereas eight samples totalling 2,473 participants $(\chi=309.1)$ correlated climate perceptions with PApp and PAv goals. PTMC demonstrated a moderate positive association with MApp goals, a small positive correlation with MAv goals, and a small positive association with PApp goals. PEPC demonstrated moderate positive associations with both PApp and PAv goals, and a small positive association to MAv goals (for details see Table 3).

Self perceptions and performance. A range of outcomes associated with self perceptions and performance in achievement contexts have been associated with PMC. For example, perceived competence represents an individual's belief in their ability to accomplish a given task or skill, and can be separated from self-esteem (one's overall appraisal of the self as a person) and physical self-perception (the appraisal of one's own physical fitness and body attractiveness; Dweck, 1986). Theory predicts that a PTMC is more likely to foster high perceptions of competence, whereas a PEPC creates an increased likelihood of diminishing competence perceptions - because only winning is good enough (see Duda, 1992). As an additional consideration, three studies broke down perceived competence into norm-referenced and self-referenced forms (Boixadós, Cruz, Torregrosa \& Valiante, 2004; Eys et al., 2013; MacDonald, Côté, Eys \& Deakin, 2011), which presumably would correlate positively with PEPC and PTMC, respectively.

Fifty-three samples with a total of 14,143 participants $(\chi=266.6)$ correlated PTMC with perceived competence, returning an overall positive association that was small and homogeneous $\left(\rho_{\mathrm{c}}=0.24, \mathrm{CI}=0.21-0.28\right)$. Fifty-one studies $(\Sigma \mathrm{n}=12,935, \chi=253.6)$ examined PEPC's 
INTRAPERSONAL CORRELATES OF MOTIVATIONAL CLIMATES

1 relationship with perceived-competence, demonstrating no overall association (see Table 3). For the specific examination of whether competence was self- or norm-referenced, three studies $(\Sigma \mathrm{n}=$ $1,979, \chi=659.7)$ examined these relationships, with PTMC showing a moderate positive homogeneous association to self-referenced perceived competence $\left(\rho_{c}=0.48, C I=0.38-0.58\right)$, but no association to norm-referenced competence perceptions. In contrast, PEPC returned a moderate positive homogeneous association to norm-referenced perceived competence $\left(\rho_{c}=0.39\right.$, $\mathrm{CI}=0.21-0.56$ ), but no association to self-referenced competence perceptions. Regarding confidence and self-esteem, five samples $\left(\sum \mathrm{n}=1,105, \chi=221\right)$ examined perceptions of self-esteem and confidence with reference to the self, as opposed to the specific task or skill. Following the same logic as perceived competence, the properties of a PTMC should promote self-esteem and confidence, whereas a PEPC should either show no association or a negative association. In support of these predictions, the analysis suggested a moderate, positive and homogeneous association to PTMC $\left(\rho_{c}=0.40, C I=0.28-0.53\right)$, and a small, negative homogeneous association to PEPC $\left(\rho_{\mathrm{c}}=-0.14, \mathrm{CI}={ }^{-0} 0.42-{ }^{-} 0.15\right)$.

Physical self-perceptions refer to specific beliefs about one's physical conditioning, fitness, and body attractiveness, and can be separated from perceived competence (task specific) and global self-esteem. Where studies included the sport competence subscale of the PSPP questionnaire, this was coded under perceived competence. The same theoretical tenets as deployed above predict that a PTMC should link to enhanced physical self-perceptions, whereas PEPC is not conducive to supporting physical self-perceptions. However, 13 studies $\left(\sum \mathrm{n}=2,477\right.$, $\chi=190.5$ ) correlated physical self-perceptions with perceptions of the motivational climate, with the analysis suggesting no associations to either PTMC or PEPC (see Tables 2 and 3).

Turning away from self-perceptions to objective performance measures, a total of 11 studies $\left(\sum \mathrm{n}=2,975, \chi=270.5\right)$ reported associations between the perceived motivational climate and objective indices of performance. Measures of performance included win:loss percentage 
INTRAPERSONAL CORRELATES OF MOTIVATIONAL CLIMATES

1 (Cumming, Smoll, Smith \& Grossbard, 2007), cardiovascular fitness (Brown \& Fry, 2013; Wang

2 et al., 2010), teacher- or coach-evaluated skill level (Bortoli et al., 2011; Yoo, 1999), and one-

3 mile run time (Xiang, Bruene \& McBride, 2004). Following the theoretical logic of perceived competence, a PTMC may be proposed to promote performance, whereas, a PEPC may demonstrate either no relationship or a negative relationship (cf. Harwood et al., 2008). Overall, PTMC demonstrated a small, positive and homogeneous association to objective performance $\left(\rho_{c}\right.$ $=0.25, \mathrm{CI}=0.15-0.35)$, whereas PEPC showed no relationship (see Table 3 ).

Perceived autonomy refers to the degree to which athletes "engage in the activity for their own valued reasons and feel that they have freely chosen to be involved"' (Allen \& Hodge, 2006; p. 267). A total of 14 samples $\left(\sum \mathrm{n}=4,233, \chi=302.4\right)$ reported associations between the perceived motivational climate and the perception that one's psychological need for autonomy was satisfied. Ames' (1992) TARGET framework and the task-mastery items in many of the questionnaires clearly assume that a PTMC should include, and so positively correlate with, perceived autonomy. The same reasoning suggests that a PEPC should either be negatively correlated or show no association. Supporting these predictions, PTMC demonstrated a moderate, positive and homogeneous relationship with perceived autonomy $\left(\rho_{c}=0.32, C I=0.20-0.45\right)$, whereas PEPC demonstrated a small negative and homogenous association $\left(\rho_{\mathrm{c}}=-0.18, \mathrm{CI}={ }^{-}\right.$ 0.28-0.08 - see Table 3).

Perceived relatedness refers to "a concern about connections with others and the quality of our interpersonal relationships" (Allen \& Hodge, 2006; p.268). A total of 11 studies ( $\sum \mathrm{n}=$ $3,416, \chi=310.8$ ) reported associations between the perceived motivational climate and the perception that one's psychological need for relatedness was satisfied. Theoretically, a PTMC may promote feelings of relatedness, whereas a PEPC should undermine such feelings (cf. Duda, 2001; Ntoumanis, 2001). Supporting these predictions, PTMC demonstrated a large, positive and homogeneous relationship with perceived relatedness $\left(\rho_{c}=0.55, \mathrm{CI}=0.46-0.64\right)$, whereas PEPC demonstrated a moderate negative and homogenous association $\left(\rho_{\mathrm{c}}=-0.36, \mathrm{CI}=-0.47-{ }^{-} 0.25-\mathrm{see}\right.$ 
INTRAPERSONAL CORRELATES OF MOTIVATIONAL CLIMATES

1 Table 3).

Motivational regulation processes. Self-determination theory (Deci \& Ryan, 1985) posits a spectrum of types of motivational regulation, based around the amount of external inducement required/perceived in order to complete a given task, or participate in a certain activity (Vallerand \& Fortier, 1998). At one end of the spectrum is intrinsic motivation (IM), which can be defined as the impetus to perform an activity for its own sake - for the pleasure and satisfaction inherent in participating in a task (Deci, 1975; Deci \& Ryan, 1985) - i.e., no external inducement is required (or perceived). At the other end of the spectrum, extrinsic motivation (or more specifically, external regulation - ER) refers to engaging in an activity as a means-to-an-end (Vallerand \& Fortier, 1998), or for instrumental behaviours, which are motivated by expected outcomes or inducements (Ryan \& Deci, 2008). In between these two extremes are several different levels/types of extrinsic motivation, including: introjected (avoiding external disapproval, seeking external approval); and identified (relating to internally held but learned values/contingencies). In addition, SDT conceptualises a state of amotivation - a state of not having any intention or energy directed towards action; characterised by a belief that success is not possible and the task is not valuable.

With questionnaire items tapping a perceived emphasis on personal improvement and effort, a PTMC should be more closely associated to pursuing personally meaningful goals (at one's own pace, for one's own reasons) than a PEPC (see also Kavussanu \& Roberts, 1996; Sproule et al., 2007). The results of this analysis were broadly supportive of the theoretical predictions (see Tables 2 and 3). Nineteen samples correlated PTMC with intrinsic motivation $(\Sigma \mathrm{n}=5,966, \chi=303.5)$, generating an overall corrected correlation that was large and homogenous $\left(\rho_{\mathrm{c}}=0.55, \mathrm{CI}=0.48-0.62\right)$. Seventeen samples correlated PEPC with intrinsic motivation $\left(\sum \mathrm{n}=4,896, \chi=288\right)$, demonstrating no consistent pattern (see Table 3). PTMC also demonstrated positive associations with IM to know, IM for stimulation; IM for accomplishment, and identified regulation - but no consistent associations with introjected regulation, ER or 


\section{INTRAPERSONAL CORRELATES OF MOTIVATIONAL CLIMATES}

1 amotivation (see Table 2). In contrast, PEPC demonstrated no consistent associations with IM

2 (any type); identified or introjected regulation, but moderate, and homogeneous positive associations with ER and amotivation (see Table 3).

As a final consideration, eight studies constructed compound functions of motivation, using equations to calculate an overall 'relative autonomy index' or overall self-determined motivation. The way the scores are calculated puts a strong emphasis on more intrinsic forms of motivation and so, in line with the above reasoning, PTMC should be positively associated with these scores, and PEPC should not. Once again, this prediction was supported, with PTMC generating a large, positive and homogeneous association with compound motivation $(k=58, \Sigma \mathrm{n}$ $\left.=2,296, \chi=287.0, \rho_{\mathrm{c}}=0.51, \mathrm{CI}=0.38-0.64\right)$ and a small, negative and homogeneous association between PEPC and compound motivation $\left(\rho_{\mathrm{c}}={ }^{-0} 0.10, \mathrm{CI}={ }^{-0} 0.20-^{-0} 0.002\right)$. 
INTRAPERSONAL CORRELATES OF MOTIVATIONAL CLIMATES

1 negative thoughts and worries $\left(\sum \mathrm{n}=2,285, \chi=134.41\right)$. The analysis suggested an overall small, negative and heterogeneous association with PTMC $\left(\rho_{\mathrm{c}}={ }^{-0} 0.19, \mathrm{CI}={ }^{-0} 0.26-{ }^{-} 0.11\right)$, but an overall

small, positive and homogeneous association with PEPC $\left(\rho_{\mathrm{c}}=0.19, \mathrm{CI}=0.95-0.34\right)$.

Whereas negative affect (above) refers to negative moods and emotions, positive affect refers to positive experiential states such as enjoyment, satisfaction, interest, and vigour (cf. Duda, 1998). As reviewed by Harwood et al. (2008), a PTMC should be more likely to promote these latter feelings, whereas a PEPC should demonstrate either no relationship or a negative relationship with such a construct. In this review, 39 samples correlated the perceived motivational climate with positive affect $\left(\sum \mathrm{n}=9,746, \chi=249.9\right)$. The analysis suggested an overall moderate, positive and homogeneous association with PTMC $\left(\rho_{\mathrm{c}}=0.47, \mathrm{CI}=0.42-0.53\right)$, but an overall small, negative and homogeneous association with $\operatorname{PEPC}\left(\rho_{\mathrm{c}^{-}}=-0.11, \mathrm{CI}={ }^{-} 0.18^{-}\right.$ $0.37)$.

Beliefs, values and strategies. Research has comprehensively investigated the links between PMC and a range of beliefs, personal values and strategies adopted by athletes. A total of 29 analyses $\left(\sum \mathrm{n}=6,646, \chi=229.2\right)$ correlated perceived motivational climate with factors such as attitudes towards sport or exercise (including perceived norms and expectations of cost/benefit), intentions to be active, self-reported adherence to exercise, and desire to attend future activities. Theoretically, PTMC may be more likely to promote positive attitudes and intentions towards participation, whereas a PEPC may only appeal to a small number of highly competitive individuals. Accordingly, the analysis produced an overall small, positive and heterogeneous association with PTMC $\left(\rho_{\mathrm{c}}=0.27, \mathrm{CI}=0.23-0.32\right)$, but no association with PEPC (see Table 3).

A number of studies have investigated associations between perceptions of motivational climate and the use of learning/practice and competitive strategies. A range of different psychological and behavioural strategies have been measured and these were divided into 
INTRAPERSONAL CORRELATES OF MOTIVATIONAL CLIMATES

1 adaptive and maladaptive categories. Adaptive strategies included: persistence; increased effort;

2 self-regulation; learning from practice; seeking help; co-operation; and adaptive coping (e.g.,

3 solution focussed). Maladaptive strategies included: self-handicapping; maladaptive coping (e.g.,

4 avoidance); exercise dependence; and avoiding practice/training. Consistent with Roberts and

5 Treasure's (1992) predictions regarding goal orientations, we predicted that a PEPC would be

6 positively associated with maladaptive strategies but not adaptive ones. Accordingly, a PTMC

7 should correlate with adaptive learning and competitive strategies, but not maladaptive strategies.

8 In support of these predictions, 17 samples $\left(\sum \mathrm{n}=4,457, \chi=262.2\right)$ correlated perceived

9 motivational climate with adaptive strategies, which demonstrated a moderate, positive and homogeneous association with PTMC $\left(\rho_{c}=0.47, \mathrm{CI}=0.36-0.57\right)$, but no association with PEPC (see Table 3$)$. Likewise, eight analyses $\left(\sum \mathrm{n}=1,767, \chi=220.9\right)$ correlated perceived motivational climate with maladaptive strategies, which demonstrated a small, negative and heterogeneous association to PTMC $\left(\rho_{\mathrm{c}}={ }^{-} 0.13, \mathrm{CI}={ }^{-} 0.22-^{-} 0.05\right)$, and a small, positive and heterogeneous association to PEPC $\left(\rho_{\mathrm{c}}=0.28, \mathrm{CI}=0.21-0.35\right)$. 
$1 \quad 0.24, \mathrm{CI}=0.12-0.36)$, but no association with PEPC. In contrast, $11\left(\sum \mathrm{n}=3,980, \chi=361.8\right)$

samples correlated antisocial attitudes with perceived motivational climate, wherein PTMC showed a small negative and homogeneous association $\left(\rho_{\mathrm{c}}={ }^{-} 0.23, \mathrm{CI}={ }^{-0} 0.34-^{-0} 0.12\right)$ and PEPC returned a moderate positive and homogeneous association $\left(\rho_{\mathrm{c}}=0.33, \mathrm{CI}=0.25-0.42\right)$.

Dispositions and Traits. Several of the correlations identified in this review represented relatively stable demographic, dispositional or personality characteristics. Thirteen samples $(\Sigma \mathrm{n}=$ $3,563, \chi=274.1)$ correlated age or playing experience to perceptions of motivational climate. With age and progression, athletes may experience an increased emphasis on winning and competition as they progress towards higher levels (i.e., with age). However, neither PTMC nor PEPC demonstrated a relationship with age or experience (see Tables 2 and 3). Notably, the majority of sample used narrow age ranges (closely aligned to those at the beginning of the Results section) and none of the studies examining age or experience sampled participants over the age of 21 years.

Perfectionism is a personality trait characterised by a person's striving for flawlessness: setting excessively high standards for oneself and being overly self-critical if these standards are not met (Flett \& Hewitt, 2002; Stoeber \& Childs, 2010). Theoretically, both task- and egooriented approaches to defining success offer opportunities for individuals to set unrealistically high standards. In this analysis, eight samples $\left(\sum \mathrm{n}=4,843, \chi=605.4\right)$ correlated perceived motivational climate with perfectionism, suggesting no association with PTMC (See Table 2) but a moderate positive and homogeneous association to PEPC $\left(\rho_{\mathrm{c}}=0.49, \mathrm{CI}=0.39-0.58\right)$.

Six samples $\left(\sum \mathrm{n}=3,858, \chi=643.0\right)$ correlated perceived motivational climate with trait flow: the general tendency of the individual to experience flow. Flow describes subjective experiences of intense, deeply involved concentration, loss of self-consciousness, and a feeling of total control that are often associated with peak performance (Csikszentmihalyi, 2002; Jackson \& Csikszentmihalyi, 1999). Theoretically, PTMCs are likely to be more positively associated with reports of dispositional flow, whereas, PEPCs appear likely to undermine many of the conditions 
INTRAPERSONAL CORRELATES OF MOTIVATIONAL CLIMATES

1 necessary for flow (Kowal \& Fortier, 2000). In support of these predictions, PTMC demonstrated

2 a moderate positive and homogeneous association to dispositional flow $\left(\rho_{c}=0.45, C I=0.39-\right.$

3 0.51), but no association was evident for PEPC (details in Table 3).

\section{Correlates below threshold. Two studies examined the correlations of perceived} motivational climate to beliefs about the purpose of sport (Ommundsen et al., 1998; Wang et al., 2008), suggesting a positive association between PTMC and beliefs that sport fosters mastery, life skills or citizenship. In contrast, PEPC was linked to the belief that sport is an opportunity to gain status. Likewise, two studies examined the association of perceived motivational climate to the beliefs about the causes of success in sport (Cury et al., 2002; Chian \& Wang, 2008), suggesting an association between PTMC and effort/learning beliefs versus an association between PEPC and ability beliefs. Finally, one study correlated climate perceptions with sources of satisfaction, linking PTMC to mastery as the source of satisfaction and superior ability as the source of satisfaction when a PEPC was reported (Ommundsen et al., 1998).

\section{Risk of Bias Assessment}

Inter-rater reliability indicated adequate percentage of agreement (96.2\%) for the 520 checked items (Supplementary Table 1). No studies undertook a random sampling process, with all studies using either purposive or opportunistic sampling. Ninety-four studies (90.4\%) provided an adequate description of the study sample, 97 studies (93.3\%) provided valid measurements of the perceived motivational climate, and 88 studies (84.6\%) provided evidence of acceptable validity for correlates. Fifty studies (48.1\%) adjusted for covariates, and eight studies $(7.7 \%)$ included data on the correlations of motivational climate subscales.

\section{Discussion}

This systematic review set out to detail the intrapersonal correlates of perceived motivational climate, the theoretical explanations for these associations, and the overall findings in relation to each correlate. With a focus on research within sport and physical activity between 1990-2014, the findings enable not only a summary of the extant literature, but a critical review of 
INTRAPERSONAL CORRELATES OF MOTIVATIONAL CLIMATES

1 current methodologies and paradigms in this field of research.

\section{Summary of Findings}

Overall, PTMCs demonstrated positive associations to a range of highly adaptive constructs, including: perceived competence (overall and self-referenced); confidence/selfesteem; feelings of autonomy and relatedness; more intrinsic forms of motivational regulation; positive affect; attitudes and intentions; objective performance measures; adaptive practice/competitive strategies; pro-social moral functioning; and dispositional flow. Likewise, PTMCs showed small negative associations to several maladaptive constructs, such as: negative affect; maladaptive practice/competitive strategies; and antisocial moral functioning. However, PEPCs were positively associated to: norm-referenced competence evaluations; external and amotivated forms of motivational regulation; negative affect; negative thoughts/worries; maladaptive practice/competitive strategies; and antisocial moral functioning. Further, PEPCs demonstrated negative associations with several adaptive outcomes such as feelings of autonomy (small), relatedness (moderate) and positive affect (small). Clearly, when considering the averageof-averages, those perceiving a task-mastery motivational climate engage in sport and physical activity more favourably. These findings are consistent with both theoretical predictions and previous reviews (e.g., Ntoumanis \& Biddle, 1999; Harwood et al., 2008). PTMCs were associated with 24 intrapersonal correlates, including four large effect sizes (intrinsic motivation, compound motivation, IM to seek stimulation, and perceived relatedness). PEPCs were associated with 15 correlates, with no large effect sizes. This pattern is consistent with the narrative review of Harwood et al. (2008) wherein PEPCs offered fewer concrete hypotheses due to the moderation effects of perceived competence.

\section{Critical Issues and Opportunities for Progress}

A broad overview of the data from this review reveals several noteworthy trends. First, there is a clear discrepancy in the number of studies examining different correlates, with goalorientations, perceived competence and affective states receiving disproportionate attention. A 
INTRAPERSONAL CORRELATES OF MOTIVATIONAL CLIMATES

1 fraction of the number of studies published examining these correlates would have been sufficient to demonstrate an association worthy of further exploration. However, in the broader literature, very few studies have attempted to establish the direction of causality in these relationships. In contrast, some important correlates have received relatively sparse attention. For example, objective measurements were rare - having to be combined into one category of objective performance measures. The pragmatic difficulties of making large-scale measurements of objective performance/behavioural data, as well as the theoretical emphasis on the subjective meaning of achievement contexts (cf. Ames, 1992b; Treasure et al., 2001) may be responsible for

this trend. However, in order for research findings to produce meaningful recommendations about the objective determinants (and outcomes) of climate perceptions, it may be necessary to introduce some more ambitious and innovative measurement techniques.

Linked to this first point, only five out of 54 (total) correlates (or put differently, $k=80$ out of 525, or $15 \%$ ) were related to behaviour and behavioural intentions: objective performance, practice and competitive strategies (adaptive or maladaptive), and moral functioning (prosocial or antisocial behaviour). One, age/experience, was demographic, but the remaining 48 correlates were cognitive or affective. In effect, this current body of research permits the conclusion that those perceiving a PTMC may think or feel more adaptively, but information regarding important behavioural outcomes is much less evidenced. Further, $42 \%$ of effect sizes focussing on behaviour were heterogeneous, versus $30 \%$ of the cognitive and affective correlates (including non-significant). This difference may indicate moderation effects such as methodological issues or more complex causal chains. Of the 12 effect sizes calculated for behavioural correlates, four were below 0.1 , six were small and two were moderate. None were large. Future research may contribute meaningfully to current understanding by continuing to explore the behavioural associations of perceived (and objective) motivational climates.

Second, the vast majority of the current research focuses on perceptions of the climate exclusively 'created by' the coach (59) or teacher (34) (although it is debated as to whether the 
INTRAPERSONAL CORRELATES OF MOTIVATIONAL CLIMATES

1 PMCSQ-2 items truly refer to the coach or the more general level of 'on this team' - cf. Harwood et al., 2008; Keegan et al., 2010a). Only five papers examined perceptions of the 'peer created' climate, and three measured perceptions of the 'parent created' climate. This raises the issues of both an under-emphasis on parents and peers, as well as the more integrated matter of failing to comprehend the concurrent or interactive influence of these social agents. Only three papers examined such perceptions concurrently (Morris \& Kavussanu, 2008; Vazou et al., 2006; White, Kavussanu \& Guest, 1998), and whilst other papers have also attempted such analyses (Carr \& Weigand, 2001; Chan, Lonsdale \& Fung, 2012), the issues remains unresolved, largely due to the use of different questionnaires for each social agent (cf. Keegan et al., 2009; 2010b; 2014a; b).

Athletes may experience the motivational 'pull and push' from the varying social agents who, together, contribute to an overall motivational climate. Therefore, examining the interactive effects of different social agents would advance knowledge on how sensitive athletes may be to specific aspects of the motivational climate. Such research is important where social agents promote conflicting messages: a common situation yet one where the current literature would not be able to predict what outcomes to expect. Thirteen years after having been identified by Duda (2001), it is increasingly important that issues such as this are addressed so that interventions can focus on specific messages, and from specific social agents, that are perceived to be most influential.

Thirdly, from a demographic perspective, the samples were relatively homogeneous in terms of using school and college participants tightly concentrated around the mean age of 16.5 years. Only 20 studies (19.2\%) reported average ages outside one standard deviation of this mean (eight below, and 12 over), with only two studies examining groups over 30 years of age (Huddleston, Fry \& Brown, 2012; Kowal \& Fortier, 2013). There may be important questions left unanswered by neglecting to examine groups outside this age-range. Further, there has been a relative lack of research into higher-level performers (only $4.8 \%$ of research examined adult national, international, and professional athletes). Yet at higher competitive levels the contextual 
INTRAPERSONAL CORRELATES OF MOTIVATIONAL CLIMATES

1 behaviour of coaches and peers may have more critical personal, financial and organisation-

2 related impacts than the youth or student-athlete.

Fourth, the vast majority of the studies sampled were cross-sectional in nature, and even those that repeated their measures did so within a relatively short time (e.g., the same season). The perceived (and objective) motivational climate may change substantially as one progresses and matures through childhood into youth, and from recreation to competition to retirement. Further, there is good reason to propose that the key influences on climate perceptions change as the career develops (Carr, Weigand \& Hussey, 1999; Keegan et al., 2014b). As noted in the prior

paragraph, only five studies recruited samples that would truly be considered elite (i.e., not counting high-performing youth athletes), and yet studying the differences between levels and career stages may well advance current understanding.

Finally, there was a relative lack of papers examining individual sports (12.5\%; e.g., tennis participants, track and field athletes, dancers, Winter Olympics athletes) as opposed to team sports, mixed samples, and PE. There is reason to believe that different socio-motivational environments may exist in team-versus-individual sports, and that an individual athlete's support network will differ as a result (e.g., the 'team' around an athlete). Accurate measurement of perceived motivational climate would therefore necessitate the development of instrumentation that is grounded in an understanding of individual sport settings. In the current review, a questionnaire developed from, and designed for, team sport populations (PMCSQ-2), has been the prominent measure of choice. However, none of these existing studies offer a clear justification of the measure's validity to examine individual sports performers. Alongside the recently developed PeerMCYSQ (Ntoumanis \& Vazou, 2005) - also developed using team sports - there is need for future research to consider more valid and appropriate assessments of athletes in individual sports, as well as more research in these contexts overall.

Subjective-objective tensions. In relation to subjective-versus-objective issues with the measurement (and interpretation) of perceived motivational climate, Treasure et al. (2001) were 
1 relatively clear in stating that:

It is true that Nicholls [1989] speaks of the objective characteristics of achievement contexts which "set the stage," or increase the tendency for task or ego involvement to be invoked. However, this does not mean that Nicholls suggests the objective reality always equates to the individual's subjective reality (pp.319 - italics original).

Keegan et al. $(2010 ; 2014 b)$ have critiqued the issue of making recommendations to coaches or teachers on the basis of subjective perceptions, which can vary substantially even when players have the same coach/teacher (Papaioannou, 1994; Cumming et al., 2007). Further still, Sproule et al. (2007; p.1047) concluded: "There is a need to examine the discrepancy between teachers' and pupils' perceptions of motivational climate compared to the behaviourally measured structures. Understanding the differences in perception and behaviour may help to guide more effective interventions." In spite of these issues, 57 studies (54.8\%) made explicit recommendations that coaches, teachers, parents or practitioners should change their behaviour after measuring participants' subjective perceptions of the motivational climate (summary Table available on request). Justifying such recommendations requires care when objective measurements of coach/teacher/parent/peer behaviours were not taken. This issue is particularly problematic when the direction (and, for that matter, the presence) of causality between perceived climate and the desired 'outcomes' can never be established through correlational (and largely cross-sectional) studies (cf. Aldrich, 1995). Correlation is a necessary but not sufficient condition for establishing causality. Research establishing exactly how social agents are able to influence participants' perceptions of the motivational climate would be valuable for informing the development of motivational climate interventions and evidence-based behavioural recommendations. As such, the objective instruments currently being developed also show promise (Morgan \& Kingston, 2010; Tessier et al., 2013), notwithstanding the issue below related to 'constrained/selective measurement'. Recent educational interventions and field-based experiments have demonstrated that both climate perceptions and associated motivational and 
INTRAPERSONAL CORRELATES OF MOTIVATIONAL CLIMATES

1 emotional indices can be influenced at the same time, suggesting a level of causal connectedness

2 not offered by correlational studies (e.g., Smith, Smoll \& Cumming, 2007; Smoll, Smith \&

3 Cumming, 2007; Standage, Treasure, Hooper, \& Kuczka, 2007). Further fine grained analyses

4 of how climate perceptions are influenced (a) by certain behaviours and language, (b) in

5 certain situations/contexts, and (c) in certain combinations, may add to this growing body of

6 applied research.

Measurement choices: Levels and constraints. Following from the above, it is worth

noting that, conceptually, a motivational climate - in its broader objective sense - can influence many more factors than task- or ego-goals. Further, the behaviours, exchanges, perceptions and attitudes that may contribute to the perceptions of either a PTMC or PEPC are likely constantly changing and interacting. Indeed, the goal-related cues, structures, expectancies and reinforcement behaviour that can comprise a motivational climate may change moment-tomoment, between sessions, and between practice and competition. However, to date, motivational climate research has almost exclusively measured: (a) very generalised (or 'contextual level' - cf. Vallerand, 1997) perceptions of the climate; (b) relatively infrequently (either once or at the beginning and end of a season); (c) using questionnaires that only assess (or at least only analyse) higher order perceptions of PMTC or PEPC (only $7.7 \%$ of the papers samples examined the lower-order climate subscales); and (d) without analysing the effects of individuals being 'nested' within teams or clubs (cf. Harwood, Beauchamp \& Keegan, 2014). Further still, questionnaire design processes invariably attempt to minimise cross loading and interactivity, even though these properties may be at the heart of a real motivational climate. This heavy dependence on questionnaire methodology, and analyses predicated chiefly on correlation, may be significantly constraining the ability of researchers to detect and account for other important influences. Influences that might only be discoverable via different methodologies and theoretical approaches (Biddle, 2000; Brustad, 1999; Culver et al., 2003). Attempts to progress research in this area may wish to examine more situational and short-term perceptions of the climate. Further still, future 


\section{INTRAPERSONAL CORRELATES OF MOTIVATIONAL CLIMATES}

1 research may wish to deploy analytic categories other than task- and ego-involving, which may be unduly constraining our observations to guarantee that research only finds climate characteristics consistent with these two categories. Recent attempts to develop measures assessing 'caring climate' (Newton et al., 2007) and 'empowering climate' (Sarrazin et al., 2013) represent progress, without necessarily addressing all of the above-described issues.

Risk of bias considerations. In reviewing the risk-of-bias assessment, it is notable that

none of the studies deployed random sampling from the target populations, but rather

opportunistic or purposive sampling. Such a strategy at the broad level of a research programme may introduce a risk of bias, which is reinforced when considering the age-range issues discussed above. Whilst the absence of ages was the main reason for insufficient population details, over half the studies sampled did not clearly attempt to manage covariates such as age, gender, ethnicity and socio-economic status. Whilst these issues were not the focus of such studies, they are some of the most common confounding variables in scientific research (Weiner, Schinka \& Velicer, 2012) and should arguably be examined as standard practice. A small proportion of studies either failed to report reliability values for all relevant variables or continued the analysis using variables with inadequate reliability. In discussing this issue, Chatzisarantis and Stoica (2009) were clear that such reporting practices should generally be discouraged in order to facilitate subsequent research syntheses. Following criticisms of 'failsafe N' procedures (Becker, 2005; Evan, 1996) and the recommendation not to use the procedure in Cochrane reviews (Higgins \& Green, 2011); this calculation was not included in the current systematic review.

\section{Limitations}

The current study attempted to systematically review a thriving and complex literature on the correlations of motivational climate perceptions in sport and physical activity. In establishing a manageable sample (of approximately 100 papers) and a coherent analysis, two key issues are notable. First, there remain additional unpublished papers not included in this analysis, although the very aims of the study were not to correct for publication bias so much as to accept it as 
INTRAPERSONAL CORRELATES OF MOTIVATIONAL CLIMATES

1 unavoidable and critically analyse the resultant literature. Further, the use of a conservative

2 analysis technique should partly ameliorate such concerns. Second, the current analysis did not

3 include interpersonal correlates, such as feelings towards the coach/teacher, team cohesion or

4 parental pressure. While such considerations may also interact with or moderate the intrapersonal

5 correlations of climate perceptions, such an analysis would have been beyond the scope of a

6 single paper. As such, the title, aims and analysis all focus on intrapersonal correlates, but future

7 research should include the consideration of interpersonal factors given that the literature on

8 intrapersonal correlations is relatively established.

\section{Charting Avenues for Future Research}

Overall, the literature examining the intrapersonal correlates of perceived motivational climate has tended to progress by: a) finding new correlates of perceived climate, or new contexts/populations in which such correlations can be found. This approach might be considered progress through expanding the applicability of the perceived motivational climate construct; $b$ ) using deductive and complex statistical procedures - such as structural equation modelling and multiple regression - to achieve progress through mapping patterns of associations between climate perceptions and their correlates. The a priori specification of which variables are 'predictors' or 'determinants' in such models, and the creation of diagrams with arrows flowing, for example, from left to right can often give the impression of causal relationships. However, the acceptance of such directionality in correlational relationships depends on the acceptance of the theory and hypotheses as true in advance - an issue which warrants critical examination and reflection across this field-of-research.

Neither of the above strategies permit the strict testing of a theory, nor do they attempt to falsify the theory, but rather they are strategies aimed at expanding and 'fleshing out' our understanding of AGT as applied to motivational climates in sport and physical activity. Even despite their very different viewpoints, both Kuhn (1962) and Popper (1969) agreed that, overall, the most substantial scientific progress is made when attempts are made to find out where, how 
1 and why theories fail, and where modifications are needed. Ultimately, the most significant

2 advances in scientific progress are achieved through the development of new explanatory theories

3 that offer new hypotheses for testing - even though they are often initially criticised for being unusual/different, too complex, unpalatable or 'too new' (i.e., unheard of, cf. Trafimow \& Rice, 2009).

In response to the specific issues identified in the above discussion there are, of course, opportunities to further explore any correlates where insufficient data currently existed, or where moderation was suggested by heterogeneous variances. Likewise, there are opportunities to expand the age-ranges sampled; to sample more from elite sport; and to sample a wider variety of activities beyond PE and team sports (particularly individual sports). Further still, there is clear scope to examine social influences other than the coach or teacher, and to examine concurrent influences, as well as to take a developmental or transitional perspective by exploring the long-term changes to climate perceptions with age and experience. As immediate opportunities identified by this review, 
INTRAPERSONAL CORRELATES OF MOTIVATIONAL CLIMATES

\section{References}

Abrahamsen, F. E., Roberts, G. C., \& Pensgaard, A. M. (2008). Achievement goals and gender effects on multidimensional anxiety in national elite sport. Psychology of Sport and Exercise, 9, 449464. DOI: 10.1111/j.1600-0838.2007.00707.

Abrahamsen, F. E., Roberts, G. C., Pensgaard, A. M., \& Ronglan, L. T. (2008). Perceived ability and social support as mediators of achievement motivation and performance anxiety. Scandinavian Journal of Medicine and Science in Sports, 18, 810-821.

Alderson, P., \& Green, S. (2008). Cochrane Collaboration open learning materials for reviewers. The Cochrane Collaboration.

Aldrich, J. (1995). Correlations genuine and spurious in Pearson and Yule. Statistical Science, 10, 364-376.

Allen, J. B. \& Hodge, K. (2006). Fostering a learning environment: Coaches and the motivational climate. International Journal of Sport Science and Coaching, 1, 260-277.

Ames, C. (1992a). Classrooms: Goals, structures, and student motivation. Journal of Educational Psychology, 84, 261- 271.

Ames, C. (1992b). Achievement goals, motivational climate, and motivational processes. In G. C. Roberts (Ed.) Advances in motivation in sport and exercise. pp. 161-176. Champaign, IL: Human Kinetics.

Appleton, P. R., Hall, H. K., \& Hill, A. P. (2011). Examining the influences of the parent-initiated and coach-initiated motivational climates upon athletes' perfectionistic cognitions. Journal of Sports Sciences, 29, 661-671. DOI: 10.1080/02640414.2010.551541

Balaguer, I., Duda, J. L., \& Crespo, M. (1999). Motivational climate and goal orientations as predictors of perceptions of improvement, satisfaction and coach ratings among tennis players. Scandinavian Journal of Medicine and Science in Sports, 9, 381-388.

Barkoukis, V., \& Hagger, M. S. (2013). The trans-contextual model: perceived learning and performance motivational climates as analogues of perceived autonomy support. European 
INTRAPERSONAL CORRELATES OF MOTIVATIONAL CLIMATES Journal of Psychology of Education, 28, 353-372. DOI: 10.1007/s10212-012-0118-5

Becker, B. J. (2005). Failsafe N or file-drawer number. In: Rothstein H. R., Sutton A. J., Borenstein M. (Eds). Publication bias in meta-analysis. Chichester (UK): John Wiley \& Sons.

Biddle, S. J. H. (2000). Psychology of sport and exercise: Present and future. Psychology of Sport and Exercise, 1, 1-5.

Biddle, S., Cury, F., Goudas, M., Sarrazin, P., Famose, J. P. \& Durand, M. (1995). Development of scales to measure perceived physical education class climate: A cross-national project. British Journal of Educational Psychology, 65, 341-358.

Biddle, S. J. H., Wang, C. K. J., Chatzisarantis, N. L. D., \& Spray, C. M. (2003). Motivation for physical activity in young people: Entity and incremental beliefs about athletic ability. Journal of Sports Sciences, 21, 973-989. DOI: 10.1080/02640410310001641377.

Blumenfeld, P. C. (1992). Classroom learning and motivation - clarifying and expanding goal theory. Journal of Educational Psychology, 84, 272-281.

Boardley, I. D., \& Kavussanu, M. (2009). The influence of social variables and moral disengagement on prosocial and antisocial behaviours in field hockey and netball. Journal of Sports Sciences, 27, 843-854. DOI: $10.1080 / 02640410902887283$

Boixados, M., Cruz, J., Torregrosa, M., \& Valiente, L. (2003). Relationships among motivational climate, satisfaction, perceived ability and fair play attitudes in young soccer players. Journal of Applied Sport Psychology, 16, 301-317. DOI: 10.1080/10413200490517977

Bortoli, L., Bertollo, M., Comani, S., \& Robazza, C. (2011). Competence, achievement goals, motivational climate, and pleasant psychobiosocial states in youth sport, Journal of Sports Sciences, 29, 171-180.

Bortoli, L., Bertollo, M., Filho, E., \& Robazza, C. (2013). Do psychobiosocial states mediate the relationship between perceived motivational climate and individual motivation in youngsters? Journal of Sport Sciences, 32, 572-582. DOI:10.1080/02640414.2013.843017

Bortoli, L., Bertollo, M., \& Robazza, C. (2009). Dispositional goal states, motivational climate, and 
INTRAPERSONAL CORRELATES OF MOTIVATIONAL CLIMATES psychobiosocial states in youth sport. Personality and Individual Differences, 47, 18-24. DOI:10.1016/j.paid.2009.01.042

Bortoli, L., Messina, G., Zorba, M., \& Robazza, C. (2012). Contextual and individual influences on antisocial behavior and psychobiosocial states of youth soccer players. Psychology of Sport and Exercise, 13, 397-406. DOI:10.1016/j.psychsport.2012.01.001

Boyce, B. A., Gano-Overway, L. A., \& Campbell, A. L. (2009). Perceived motivational climate's influence on goal orientations, perceived competence, and practice strategies across the athletic season. Journal of Applied Sport Psychology, 21, 381-394. DOI:10.1016/j.psychsport.2005.06.002

Brown, T. C., \& Fry, M. D. (2013). Associations between females' perceptions of college aerobics class motivational climates and their responses. Women \& Health, 53, 843-857. DOI:10.1080/10413200390180062

Brunel, P. C. (1999). Relationship between achievement goal orientation and perceived motivational climate on intrinsic motivation. Scandinavian Journal of Medicine and Science in Sports, 9 , 365-374.

Brustad, R. J. (1999). Editorial perspective: The contribution of the manuscript-review process to knowledge development in sport and exercise psychology. Journal of Sport \& Exercise Psychology, 21, 307-312.

Carr, S., \& Weigand, D. A. (2001). Parental, peer, teacher and sporting hero influence on the goal orientations of children in physical education. European Physical Education Review, 7, 305328. DOI: $1356-336 \mathrm{X}(200110)$.

Carr, S., Weigand, D. A., \& Hussey, W. (1999). The relative influence of parents, teachers, and peers on children and adolescents' achievement and intrinsic motivation and perceived competence in physical education. Journal of Sport Pedagogy, 5, 28-51.

Centre for Reviews \& Dissemination (2009). Systematic Reviews: CRD's guidance for undertaking reviews in health care. University of York Press, York. 
INTRAPERSONAL CORRELATES OF MOTIVATIONAL CLIMATES

1 Cervello, E. M., Jiminez, R., del Villar, F., \& Ramos, L. (2004). Goal orientations, motivational climate, equality, and discipline of Spanish physical educations students. Perceptual and Motor Skills, 99, 271-283.

Cervello, E. M., Moreno, J. A., Villodore, N. A., \& Iglesias, D. (2006). Goal orientation, motivational climate, and dispositional flow in high-school students engaged in extracurricular physical activity. Perceptual and Motor Skills, 102, 87-92.

Cervello, E. M., Santa Rosa, F. J., Calvo, T. G., Jiminez, R., \& Iglesias, D. (2007). Young tennis players' competitive task involvement and performance: The role of goal orientations, contextual motivational climate, and coach-initiated motivational climate. Journal of Applied Sport Psychology, 19, 304-321. DOI:10.1080/1041320070329134

Chan, D. K., Lonsdale, C., \& Fung, H. H. (2012). Influences of coaches, parents, and peers on the motivational patterns of child and adolescent athletes. Scandinavian Journal of Medicine and Science in Sports, 22(4), 558-568.

Christodoulidis, T., Papaioannou, A., \& Digelidis, N. (2001). Motivational climate and attitudes towards exercise in Greek senior high school: A year-long intervention. European Journal of Sport Science, 1, 1-12.

Chatzisarantis, N. L. D., \& Stoica, A. (2009). A primer on the understanding of meta-analysis. Psychology of Sport and Exercise, 10, 498-501. DOI:10.1016/j.psychsport.2009.04.003

Cohen, J. (1977). Statistical power analysis for the behavioral sciences (Rev. ed.). New York, NY: Academic Press.

Cohen J. \& Cohen. P.(1983). Applied multiple regression/correlation analysis for the behavioral sciences. Hillsdale, NJ: Erlbaum.

Cox, A. \& Williams, L. (2008). The roles of perceived teacher support, motivational climate, and psychological needs satisfaction in students' physical education motivation. Journal of Sport and Exercise Psychology, 30, 222-239.

Csikszentmihalyi, M. (2002). Flow: The psychology of optimal experience (2nd ed.). New York: 
INTRAPERSONAL CORRELATES OF MOTIVATIONAL CLIMATES Harper \& Row.

Culver, D. M., Gilbert, W. D., \& Trudel, P. (2003). A decade of qualitative research in sport psychology journals: 1990-1999. The Sport Psychologist, 17, 1-15.

Cumming, S. P., Smoll, F. L., Smith, R. E., \& Grossbard, J. R. (2007). Is winning everything? The relative contributions of motivational climate and won-lost percentage in youth sports. Journal of Applied Sport Psychology, 19, 322-336. DOI: 10.1080/10413200701342640

Cunningham, G. B., Xiang, P. (2008). Testing the mediating role of perceived motivational climate in the relationship between achievement goals and satisfaction: Are these relationships invariant across sex? Journal of Teaching in Physical Education, 27, 192-204.

Cury, F., Da Fonseca, D., Rufo, M., \& Sarrazin, P. (2002). Perceptions of competence, implicit theory of ability, perceptions of motivational climate and achievement goals: A test of the trichotomous conception of endorsement of achievement motivation in the physical setting. Perceptual and Motor Skills, 95, 233-244.

de Bruin, A. P., Bakker, F. C., \& Oudejans, R. R. D. (2009). Achievement goal theory and disordered eating: Relationships of disordered eating with goal orientations and motivational climate in female gymnasts and dancers. Psychology of Sport and Exercise, 10, 72-79.

Deci, E. L. (1975). Intrinsic motivation. New York: Plenum Publishing Co.

Deci, E. L., \& Ryan, R. M. (1985). Intrinsic motivation and self-determination in human behavior. New York: Plenum.

Dixon-Woods, M., Cavers, D., Agarwal, S., Annandale, E., Arthur, A., Harvey, J., Hsu, R., Katbamna, S., Olsen, R., Smith, L. K., Riley, R., Sutton, A. J. (2006). Conducting a critical interpretive review of the literature on access to healthcare by vulnerable groups. BMC Medical Research Methodology, 6, 35. DOI:10.1186/1471-2288-6-35.

Dixon-Woods, M., \& Fitzpatrick, R. (2001). Including qualitative research in systematic reviews: Opportunities and problems. Journal of Evaluation in Clinical Practice, 7, 125-133. DOI: 10.1046/j.1365-2753.2001.00257.x 
INTRAPERSONAL CORRELATES OF MOTIVATIONAL CLIMATES

1 Duda, J. L. (1992). Motivation in sport setting: A goal perspective approach. Motivation in sport and exercise. Champaign, Illinois: Human Kinetics, 57-92.

Duda, J. L. (1993). Goals: A social-cognitive approach to the study of achievement motivation in sport. In R. Singer, M Murphey, \& LK Tennant (Eds.), Handbook of research in sport psychology (pp. 421-436). New York: Macmillan.

Duda, J. L. (1998). Advances in sport and exercise psychology measurement. Morgantown: Fitness Information Technology.

Duda, J. L. (2001). Achievement goal research in sport: Pushing the boundaries and clarifying some misunderstandings. In: G. C. Roberts (Ed.), Advances in motivation in sport and exercise. (pp. 129-183). Champaign: IL, Human Kinetics.

Duda, J. L., \& Whitehead, J. (1998). Measurement of goal perspectives in the physical domain. In J. L Duda (Ed.), Advances in sport and exercise psychology measurement, (pp. 21-48). Morgantown, WV: Fitness Information Technology.

Dweck, C. S. (1986). Motivational processes affecting learning. American Psychologist, 41, 10401048

Elliot, A. J. (1999). Approach and avoidance motivation and achievement goals. Educational Psychologist, 34, 169-189.

Elliot, A. J., \& Church, M. A. (1997). A hierarchical model of approach and avoidance achievement motivation. Journal of Personality and Social Psychology, 72, 218-232.

Elliot, A. J., \& McGregor, H. A. (2001). A 2 X 2 achievement goal framework. Journal of Personality and Social Psychology, 80, 501-519.

Evan, S. (1996). Misleading meta-analysis: Statistician's comment. British Medical Journal, 312, 125-126.

Eys, M. A., Jewitt, E., Evans, M. B., Wolf, S., Bruner, M. W., \& Loughead, T. (2013). Coach-initiated motivational climate and cohesion in youth sport. Research Quarterly in Exercise and Sport, 84, 373-383. DOI: 10.1080/02701367.2013.814909 


\section{INTRAPERSONAL CORRELATES OF MOTIVATIONAL CLIMATES}

1 Ferrer-Caja, E., \& Weiss, M. R. (2000). Predictors of intrinsic motivation among adolescent students in physical education. Research Quarterly for Exercise and Sport, 71, 267-279.

Ferrer-Caja, E., \& Weiss, M. R. (2002). Cross-validation of a model of intrinsic motivation with students enrolled in high school elective courses. The Journal of Experimental Education, 71, $41-65$.

Flett, G L. \& Hewitt, P. L. (2002). Perfectionism. Washington, DC: American Psychological Association.

Fry, M. D., \& Newton, M. (2003). Application of achievement goal theory in an urban youth tennis setting. Journal of Applied Sport Psychology, 15, 50-66. DOI:10.1080/10413200390180062

Gano-Overway, L. A., \& Ewing, M. E. (2004). A longitudinal perspective of the relationship between perceived motivational climate, goal orientations and strategy use. Research Quarterly for Exercise and Sport, 75, 315-325. DOI:10.1080/02701367.2004.10609163.

Gano-Overway, L. A., Guivernau, M., Magyar, T. M., Waldron, J. J., Ewing, M. E. (2005). Achievement goal perspectives, perceptions of the motivational climate, and sportspersonship: individual and team effects. Psychology of Sport and Exercise, 6, 215-232.

Gao, Z., Lochbaum, M., \& Podlog, L. (2011). Self-efficacy as a mediator of children's achievement motivation and in-class physical ability. Perceptual and Motor Skills, 113, 969-981.

Giacomini, M. K., \& Cook, D. J. (2000). Users' guides to the medical literature: XXIII. Qualitative research in health care B. What are the results and how do they help me care for my patients? Evidence-Based Medicine Working Group. Journal of the American Medical Association, 284, $357-62$.

Gonzalez-Cutre, D., \& Sicilia, A. (2012). Motivation and exercise dependency: A study based on selfdetermination theory. Research Quarterly for Exercise and Sport, 83, 318-329.

Gonzalez-Cutre, D., Sicilia, A., Moreno, J. A., \& Fernandez-Balboa, J. M. (2009). Dispositional flow in physical education: Relationships with motivational climate, social goals and perceived competence. Journal of Teaching in Physical Education, 28, 422-440. 
INTRAPERSONAL CORRELATES OF MOTIVATIONAL CLIMATES

1 Goudas, M. \& Biddle, S. (1994). Perceived motivational climate and intrinsic motivation in school physical education classes. European Journal of Psychology of Education, 9, 241-250.

Grasten, A., Jaakkola, T., Liukkonen, J., Watt, A., \& Yli-Piipari, S. (2012). Prediction of enjoyment in school physical education. Journal of Sports Science and Medicine, 11, 260-269.

Halvari, H., Skjesol, K., \& Bagoien, T. E. (2011). Motivational climate, achievement goals, and physical education outcomes: A longitudinal test of achievement goal theory. Scandinavian Journal of Educational Research, 55, 79-104. DOI: 10.1080/00313831.2011.539855

Harwood, C. G., Beauchamp, M. R., \& Keegan, R. J. (2014) Group functioning through optimal achievement goals. In Beauchamp M. R. and Eys, M. A. (Eds.) Group dynamics in exercise and sport psychology. Oxford: Routledge.

Harwood, C. G., Spray, C. M., \& Keegan, R. (2008). Achievement goal theories in sport. In T. S. Horn (Ed.), Advances in sport psychology (pp. 157-185). Champaign, IL: Human Kinetics.

Higgins, J. P. T., \& Green, S. (2011). Cochrane handbook for systematic reviews of interventions. The Cochrane Collaboration.

Hogue, C. M., Fry, M. D., Fry, A. C., \& Pressman, S. D. (2013). The influence of a motivational climate intervention on participants' salivary cortisol and psychological responses. Journal of Sport and Exercise Psychology, 35, 85-97.

Huddleston, H., Fry, MD., \& Brown, T. C. (2012). Corporate fitness members' perceptions of the environment and their intrinsic motivation. Revisita de Psicoligia del Deporte, 21, 15-23.

Hunter, J. E., \& Schmidt, F. L. (2004). Methods of meta-analysis: Correcting error and bias in research findings (2nd ed.). Thousand Oaks, CA: Sage.

Isoard-Gautheur, S., Guillet-Descas, E., \& Duda, J. L. (2013). How to achieve in elite training centers without burning out. An achievement goals theory perspective. Psychology of Sport and Exercise, 14, 72-83. DOI:10.1016/j.psychsport.2012.08.001

Iwasaki, S., \& Fry, M. D. (2013). The effort of sport psychology professionals to assist sport administrators in evaluating youth sport programs. The Sport Psychologist, 27, 360-371. 
INTRAPERSONAL CORRELATES OF MOTIVATIONAL CLIMATES

1 Jackson, S., \& Csikszentmihalyi, M. (1999). Flow in sports: The keys to optimal experiences and performances. Champaign, IL: Human Kinetics.

Joesaar, H., \& Hagger, M. S. (2012). Young athletes' perceptions of autonomy support from the coach, peer motivational climate and intrinsic motivation in spot setting: One year effects. Psychology of Sport and Exercise, 13, 257-262. DOI:10.1016/j.psychsport.2011.12.001

Joesaar, H., Hein, V., \& Hagger, M. S. (2011). Peer influence on young athletes' need satisfaction, intrinsic motivation and persistence in sport: A 12-month prospective study. Psychology of Sport and Exercise, 12, 500-508. DOI:10.1016/j.psychsport.2011.04.005

Kalaja, S., Jaakkola, T., Watt, A., Liukonen, J., Ommundsen, Y. (2009). The associations between seventh grade Finnish students' motivational climate, perceived competence, self-determined motivation, and fundamental movement skills. European Physical Education Review, 15, 315335. DOI: $10.1177 / 1356336 X 09364714$

Kavussanu, M. (2006). Motivational predictors of prosocial and antisocial behavior in football. Journal of Sports Sciences, 24, 575-588.

Kavussanu, M., \& Roberts, G. C. (1996). Motivation in physical activity contexts: The relationship of perceived motivational climate to intrinsic motivation and self-efficacy. Journal of Sport and Exercise Psychology, 18, 264-280. DOI: 10.1080/02640410500190825

Kavussanu, M., Roberts, G. C., \& Ntoumanis, N. (2002). Contextual influences on moral functioning of college basketball players. The Sport Psychologist, 16, 347-367.

Kavussanu, M., \& Spray, C. M. (2006). Contextual influences on moral functioning of male youth footballers. The Sport Psychologist, 20, 1-23.

Keegan, R. J., Harwood, C. G., Spray, C. M., \& Lavallee, D. E. (2009). A qualitative investigation exploring the motivational climate in early-career sports participants: Coach, parent and peer influences on sport motivation. Psychology of Sport and Exercise, 10, 361-372. DOI: 10.1016/j.psychsport.2008.12.003 
INTRAPERSONAL CORRELATES OF MOTIVATIONAL CLIMATES

1 Keegan, R. J., Harwood, C. G., Spray, C. M., \& Lavallee, D. E. (2010a). From motivational climate to motivational atmosphere: A review of research examining the social and environmental influences on athlete motivation in sport. In B. D. Geranto (Ed.) Sport psychology. Nova Science Publishers: Hauppauge NY. ISBN 9781617289323.

Keegan, R. J., Harwood, C. G., Spray, C. M., \& Lavallee, D. E. (2014a). A qualitative investigation of the motivational climate in elite sport. Psychology of Sport and Exercise, 15, 97-107. DOI: 10.1016/j.psychsport.2013.10.006

Keegan, R. J., Spray, C. M., Harwood, C. G., \& Lavallee, D. E. (2010b). The 'motivational atmosphere' in youth sport: Coach, parent and peer influences on motivation in specializing sport participants. Journal of Applied Sport Psychology, 22, 87-104. DOI:10.1080/10413200903421267

Keegan, R. J., Spray, C. M., Harwood, C. G., \& Lavallee, D. E. (2014b). A qualitative synthesis of research into social motivational influences across the athletic career span. Qualitative Research in Sport, Exercise and Health. DOI: 10.1080/2159676X.2013.857710.

Kouli, O., \& Papaioannou, A. G. (2009). Ethnic/cultural identity salience, achievement goals and motivational climate in multicultural physical education classes Psychology of Sport and Exercise, 10, 45-51. DOI:10.1016/j.psychsport.2008.06.001

Kowal, J., \& Fortier, M. S. (2000). Testing relationships from the hierarchical model of intrinsic and extrinsic motivation using flow as a motivational consequence. Research Quarterly for Exercise and Sport, 72, 171-181.

Kristiansen, E., Halvari, H., \& Roberts, G. C. (2012). Organizational and media stress among professional football players: Testing an achievement goal theory model. Scandinavian Journal of Medicine and Science in Sports, 22, 569-579. DOI: 10.1111/j.1600-0838.2010.01259.x

Kristiansen, E., Roberts, G. C., \& Abrahamsen, F. E. (2008). Achievement involvement and stress coping in elite wrestlers. Scandinavian Journal of Medicine and Science in Sports, 18, 526-538. DOI: $10.1111 / \mathrm{j} .1600-0838.2007 .00646 . x$ 
INTRAPERSONAL CORRELATES OF MOTIVATIONAL CLIMATES

1 Kucze, P. (2013). On the possibility of applying achievement goal theory in competitive sports. Human Movement, 14, 129-137. DOI: 10.2478/humo-2013-0015

Kuczka, K. K., \& Treasure, D. C. (2005). Self-handicapping in competitive sport: influence of the motivational climate, self-efficacy and perceived importance. Psychology of Sport and Exercise, 6, 539-550. DOI:10.1016/j.psychsport.2004.03.007

Kuhn, T. S. (1962). The structure of scientific revolutions. Chicago: University of Chicago Press.

Lemyre, P. A. (2010). The psycho-physiology of overtraining and athlete burnout in swimming. XIth International Symposium for Biomechanics \& Medicine in Swimming, 11, 22-24.

Lemyre, P. A., Hall, H. K., \& Roberts, G. C. (2008). A social cognitive approach to burnout in elite athletes. Scandinavian Journal of Medicine and Science in Sports, 18, 221 - 234. DOI: 10.1111/j.1600-0838.2007.00671.

Lemyre, P. A., Roberts, G. C., \& Ommundsen, Y. (2002). Achievement Goal Orientations, Perceived Ability, and Sportspersonship in Youth Soccer. Journal of Applied Sport Psychology, 14, 120136.

Liukkonen, J., Watt, A., Barkoukis, V., \& Jaakkola, T. (2010). Motivational climate and students' emotional experiences and effort in physical education. The Journal of Educational Research, 103, 295-308. DOI: 10.1080/10413200701342640

Macdonald, D. J., Cote, J., Eys, M., \& Deakin, J. (2011). The role of enjoyment and motivational climate in relation to the personal development of team sport athletes. The Sport Psychologist, $25,32-46$.

Machida, M., Ward, R. M., \& Vealey, R. S. (2012). Predictors of sources of self-confidence in collegiate athletes. International Journal of Sport and Exercise Psychology, 10, 172-185. DOI:10.1080/1612197X.2012.672013

Magyar, T. M., \& Feltz, D. L. (2003). The influence of dispositional and situational tendencies on adolescent girls' sport confidence sources. Psychology of Sport and Exercise, 4, 175-190. DOI:10.1016/S1469-0292(01)00037-1 
INTRAPERSONAL CORRELATES OF MOTIVATIONAL CLIMATES

1 Magyar, T. M., Feltz, D. L., \& Simpson, I. P. (2004). Individual and crew level determinants of collective efficacy in rowing. Journal of Sport and Exercise Psychology, 26, 136-153.

Maykut, P. \& Morehouse, R. (1994). Beginning qualitative research - A philosophic and practical guide. London: Falmer Press.

Mi-Sook, K., Duda, J. L., \& Gano-Overway, L. A. (2011). Predicting occurrence of and responses to psychological difficulties: The interplay between achievement goals, perceived ability, and motivational climates among Korean athletes. International Journal of Sport and Exercise Psychology, 9, 31-47. DOI:10.1080/161219X.2011.563125

Miller, B. W., Roberts, G. C., \& Ommundsen, Y. (2005). Effect of perceived motivational climate on moral functioning team moral atmosphere perceptions, and the legitimacy of internationally injurious acts among competitive youth football players. Psychology of Sport and Exercise, 6, 461-477. DOI: 10.1016/j.psychsport.2004.04.003.

Moreno-Murcia, J. A., Gimeno, E. G., Gonzalez-Cutre Coll, D. (2007). Young athletes' motivational profiles. Journal of Sports Science and Medicine, 6, 172-179.

Moreno-Murcia, J. A., Gimeno, E. G., Gonzalez-Cutre Coll, D. (2008). Relationships among goal orientations, motivational climate and flow in adolescent athletes: Differences by gender. The Spanish Journal of Psychology, 11, 181-191.

Moreno-Murcia, J. A., San Roman, M. L., Galindo, C. M., Alonso, N., \& Gonzalez-Cutre, D. (2008). Peers' influence on exercise enjoyment: A self-determination theory approach. Journal of Sports Science and Medicine, 7, 23-31.

Moreno-Murcia, J. A., Sicilia, A., Cervello, E., Huescar, E., \& Dumitru, D. C. (2011). The relationship between goal orientations, motivational climate and self-reported discipline in physical education. Journal of Sports Science and Medicine, 10, 119-129.

Morgan, K., \& Carpenter, P. J. (2002). Effects of manipulating the motivational climate in physical education lessons. European Physical Education Review, 8, 207-229.

DOI: $10.1177 / 1356336 X 020083003$. 
INTRAPERSONAL CORRELATES OF MOTIVATIONAL CLIMATES

1 Morgan, K., \& Kingston, K. (2010). Promoting a mastery motivational climate in a higher education sports class. Journal of Hospitality, Leisure, Sport and Tourism Education. 9(1), 73-83. DOI:10.3794/johlste.91.236

Morris, R. L., \& Kavussanu, M. (2008). Antecedents of approach-avoidance goals in sport. Journal of Sports Sciences, 26, 465-476.

Murtagh, M. J., Thomson, R. G., May, C. R., Rapley, T., Heaven, B. R., Graham, R. H., Kaner, E. F., Stobbart, L., \& Eccles, M. P. (2007). Qualitative methods in a randomised controlled trial: the role of an integrated qualitative process evaluation in providing evidence to discontinue the intervention in one arm of a trial of a decision support tool. Quality and Safety in Health Care, $16,224-9$.

Newton, M., Detling, N., Kilgore, J., \& Bernhardt, P. (2004). Relationship between achievement goal constructs and physical self-perceptions in a physical activity setting. Perceptual and Motor Skills, 99, 757-770.

Newton, M., \& Duda, J. L. (1993). The relationship of task and ego orientation to performancecognitive content, affect, and attributions in bowling. Journal of Sport Behaviour, 16, 209-220.

Newton, M., Fry, M., Gano-Overway, L., Watson, D., Kim, M., Magyar, M., \& Guivernau, M. (2007). Psychometric properties of the Caring Scale in a physical activity setting. Revista de Psicología del Deporte, 16, 67-84.

Newton, M., Watson, D. L., Kim, M-s., \& Beacham, A. O. (2006). Understanding motivation of undeserved youth in physical activity settings. Youth and Society, 37, 348-371. DOI: $10.1177 / 0044118 X 05278964$

Nicholls, J. G. (1984). Achievement motivation: Conceptions of ability, subjective experience, task choice, and performance. Psychological Review, 91, 328-346. DOI: 10.1037//0033295X.91.3.328

Nicholls, J. G. (1989). The Competitive ethos and democratic education. Cambridge, MA: Harvard University Press. 
INTRAPERSONAL CORRELATES OF MOTIVATIONAL CLIMATES

1 Ntoumanis, N. (2001). A self-determination approach to the understanding of motivation in physical education. British Journal of Educational Psychology, 71, 225-242.

Ntoumanis, N., \& Biddle, S. J. H. (1998a). The relationship between achievement goal profile groups and perceptions of motivational climates in sport. Scandinavian Journal of Medicine and Science in Sports, 8, 120-124.

Ntoumanis, N., \& Biddle, S. J. H. (1998b). The relationship between competitive anxiety, achievement goals, and motivational climates. Research Quarterly for Exercise and Sport, 69, 176-187.

Ntoumanis, N., \& Biddle, S. (1999). A review of motivational climate in physical activity. Journal of Sports Science, 17, 643-665. DOI: 10.1080/026404199365678.

Ntoumanis, N., \& Vazou, S. (2005). Peer motivational climate in youth sport: Measurement development and validation. Journal of Sport \& Exercise Psychology, 27, 432-455.

O’Rourke, D. J., Smith, R. E., \& Smoll, F. L. (2011). Trait anxiety in young athletes as a function of parental pressure and motivational climate: Is parental pressure always harmful? Journal of Applied Sport Psychology, 23, 398-412. DOI: 10.1080/10413200.2011.552089

Ommundsen, Y., (2006). Pupils' self-regulation in physical education: The role of motivational climates and differential achievement goals. European Physical Education Review, 12, 289315. DOI: $10.1177 / 1356336 X 06069275$

Ommundsen, Y., \& Kvalø, S. E. (2007). Autonomy-mastery, supportive or performance focused? Different teacher behaviours and pupils' outcomes in physical education. Scandinavian Journal of Educational Research, 51, 385-413.

Ommundsen, Y., Roberts, G. C., \& Kavussanu. M. (1998). Perceived motivational climate and cognitive and affective correlates among Norwegian athletes. Journal of Sports Sciences, 16, 153-164. DOI: 10.1080/026404198366867.

Ommundsen, Y., Roberts, G. C., Lemyre, P. N., \& Miller, B. W. (2005). Peer relationships in adolescent competitive soccer: Associations to perceived motivational climate, achievement 
INTRAPERSONAL CORRELATES OF MOTIVATIONAL CLIMATES goals and perfectionism. Journal of Sport Sciences, 23, 977-989. DOI: 10.1080/02640410500127975.

Ommundsen, Y., Roberts, G. C., Lemyre, P. N., \& Miller, B. W. (2006). Parental and coach support or pressure on psychosocial outcomes of pediatric athletes in soccer. Clinical Journal of Sport Medicine, 16, 522-526.

Ommundsen, Y., Roberts, G. C., Lemyre, P. N., \& Treasure, D. (2003). Perceived motivational climate in male youth soccer: Relations to social-moral functioning, sportspersonship and team norm perceptions. Psychology of Sport and Exercise, 4, 397-413. DOI: 10.1016/S14690292(02)00038-9.

Papaioannou, A. (1994). Development of a questionnaire to measure achievement orientations in physical education. Research Quarterly for Exercise and Sport, 65, 11-20.

Papaioannou, A. (1995). Differential perceptual and motivational patterns when different goals are adopted. Journal of Sport and Exercise Psychology, 17, 18-34.

Papaioannou, A. (1997). Perceptions of motivational climate, perceived competence, and motivation of students of varying ages and sport experience. Perceptual and Motor Skills, 85, 419-430.

Papaioannou, A. (1998). Students' perceptions of the physical education class environment for boys and girls and the perceived motivational climate. Research Quarterly for Exercise and Sport, $69,267-275$.

Parish, L. E., \& Treasure, D. C. (2003). Physical activity and situational motivation in physical education: Influence of the motivational climate and perceived ability. Research Quarterly for Exercise and Sport, 74, 173-182.

Pawson, R., Greenhalgh, T., Harvey, G., \& Walshe, K. (2004). Realist synthesis: an introduction. Manchester: ESRC Research Methods Programme.

Pope, C., \& Mays, N. (2006). Qualitative Research in Health Care. (3rd ed). Oxford: Blackwell. Popper, K. R. (1969). Conjectures and Refutations: The Growth of Scientific Knowledge. London: Routledge \& Kegan Paul. 


\section{INTRAPERSONAL CORRELATES OF MOTIVATIONAL CLIMATES}

1 Quested, E., \& Duda, J. L. (2010). Exploring the social-environmental determinants of well- and illbeing in dancers: A test of basic needs theory. Journal of Sport and Exercise Psychology, 32, $39-60$.

Reinboth, M., \& Duda, J. L. (2004) The motivational climate, perceived ability, and athlete's psychological and physical well-being. The Sport Psychologist, 18, 237-251.

Reinboth, M., \& Duda, J. L. (2006). Perceived motivational climate, need satisfaction and indices of well-being in team sports: A longitudinal perspective. Psychology of Sport and Exercise, 7, 2690286. DOI:10.1016/j.psychsport.2005.06.002 
INTRAPERSONAL CORRELATES OF MOTIVATIONAL CLIMATES

motivational climate and change in goal orientations among Japanese ice hockey players. International Journal of Sports Science and Coaching, 7, 81-88.

Sarrazin, P., Guillet, E., \& Cury, F. (2001). The effects of coach's task- and ego-involving climate on the changes in perceived competence, relatedness, and autonomy among girl handballers. European Journal of Sport Science, 1, 1-9.

Sarrazin, P., Smith, N., Tzioumakis, Y., Tessier, D., Quested, E., Papaioannou, A., \& Duda, J. L. (2013). Correlates of the Objectively Assessed Empowering and Disempowering Features of the Motivational Climate in Grassroots Football. European College of Sport and Exercise Science Conference, Barcelona, Spain, June 2013.

Seifriz, J. J., Duda, J. L., \& Chi, L. (1992). The relationship of perceived motivational climate to intrinsic motivation and beliefs about success in basketball. Journal of Sport and Exercise Psychology, 14, 375-391.

Sicilia, A., Moreno, J. A., \& Rojas, A. J. (2008). Motivational profiles and flow in physical education lessons. Perceptual and Motor Skills, 106, 473-494.

Smith, A. L., Balaguer, I., \& Duda, J. L. (2006). Goal orientation profile differences on perceived motivational climate, perceived peer relationships, and motivation-related responses of youth athletes. Journal of Sports Sciences, 24, 1315-1327. DOI: 10.1080/02640410500520427

Smith, M. (2010). Research methods in sport. UK: Learning Matters.

Smith, R. E., Cumming, S. P., \& Smoll, F. L. (2008). Development and validation of the motivational climate scale for youth sport. Journal of Applied Sport Psychology, 20, 116-136. DOI: $10.1080 / 10413200701790558$.

Smith, R. E., Smoll, F. L., \& Cumming, S. P. (2007). Effects of a motivational climate intervention for coaches on young athletes' sport performance anxiety. Journal of Sport \& Exercise Psychology, 29, 39-59.

Smoll, F. L., Smith, R. E., \& Cumming, S. P. (2007). Effects of a motivational climate intervention for coaches on changes in young athletes' achievement goal orientations. 
INTRAPERSONAL CORRELATES OF MOTIVATIONAL CLIMATES Journal of Clinical Sport Psychology, 1, 23-46.

Spray, C. M. (2000). Predicting participation in noncompulsory physical education: Do goal perspectives matter? Perceptual and Motor Skills, 90, 1207-1215.

Sproule, J., Wang, C. K. J., Morgan, K., McNeill, M., \& McMorris, T. (2007). Effects of motivational climate in Singaporean physical education lessons on intrinsic motivation and physical activity intention. Personality and Individual Differences, 43, 1037-1049. DOI:10.1016/j.paid.2007.02.017

Standage, M., Duda, J. L., \& Ntoumanis, N. (2003) Predicting motivational regulations in physical education: The interplay between dispositional goal orientations, motivational climate and perceived competence. Journal of Sports Sciences, 21, 631-647.

DOI: $10.1080 / 0264041031000101962$

Standage, M., Treasure, D. C., Hopper, K., \& Kuczka, K. (2007). Self-handicapping in school physical education: The influence of the motivational climate. British Journal of Educational Psychology, 77, 81-99. DOI:10.1348/000709906X103636

Stoeber, J., \& Childs, J. H. (2010). The Assessment of Self-Oriented and Socially Prescribed Perfectionism: Subscales Make a Difference. Journal of Personality Assessment, 92, 577-585.

Tessier, D., Smith, N., Tzioumakis, Y., Quested, E., Sarrazin, P., Papaioannou, A., Digelidis, N., \& Duda, J. L. (2013) Comparing the objective motivational climate created by grassroots soccer coaches in England, Greece and France. International Journal of Sport and Exercise Psychology,11, 365-383. DOI:10.1080/1612197X.2013.831259.

Theodosiou, A., \& Papaioannou. A. (2006). Motivational climate, achievement goals and metacognitive activity in physical education and exercise involvement in out-of-school settings. Psychology of Sport and Exercise, 7, 361-379. DOI: 10.1016/j.psychsport.2005.10.002.

Trafimow, D., \& Rice, S. (2009). What if social scientists had reviewed great scientific works in the past? Perspectives on Psychological Science, 4, 65-78. 
INTRAPERSONAL CORRELATES OF MOTIVATIONAL CLIMATES

1 Treasure, D. C., Duda, J. L., Hall, H. K., Roberts, G. C., Ames, C., \& Maehr, M. L. (2001). Clarifying misconceptions and misrepresentations in achievement goal research in sport: A response to Harwood, Hardy, and Swain. Journal of Sport and Exercise Psychology, 23, 317-329.

Treasure, D. C., \& Roberts., G. C. (2001). Students' perceptions of the motivational climate, achievement beliefs, and satisfaction in physical education. Research Quarterly for Exercise and Sport, 72, 165-175.

Trenz, R. C., \& Zusho, A. (2011). Competitive swimmers' perceptions of motivational climate and their personal achievement goals. International Journal of Sport Science and Coaching, 6, 433443.

Vallerand, R. J. (1997). Toward a hierarchical model of intrinsic and extrinsic motivation. In M. Zanna (Ed.) Advances in experimental social psychology, 271-360. New York: Academic Press.

Vallerand, R. J., \& Fortier, M. S. (1998). Measures of intrinsic and extrinsic motivation in sport and physical activity: A review and critique. In J. Duda (Ed.) Advances in sport and exercise psychology measurement. (pp. 83-100) Morgantown WV: Fitness Information Technology.

Van Yperen, N. W., Blaga, M., \& Postmes, T. (2014). A meta-analysis of self-reported achievement goals and nonself-report performance across three achievement domains (work, sports, and education). PLoS ONE, 9(4): e93594. DOI:10.1371/journal.pone.0093594

Vazou, S. (2010). Variations in the perceptions of peer and coach motivational climate. Research Quarterly for Exercise and Sport, 81, 199-211.

Vazou, S., Ntoumanis, N., \& Duda, J. L. (2006). Predicting young athletes' motivational indices as a function of their perceptions of the coach- and per-created climate. Psychology of Sport and Exercise, 7, 215-233. DOI:10.1016/j.psychsport.2005.08.007

Walling, M. D., Duda, J. L., \& Chi, L. (1993). The perceived motivational climate in sport questionnaire: Construct and predictive validity. Journal of Sport and Exercise Psychology, 15, $172-183$.

Wang, C. K., Lim, B. S. C., Aplin, N. G., Chia, Y. H. M., McNeill, M., \& Tan, W. K. C. (2008). 
INTRAPERSONAL CORRELATES OF MOTIVATIONAL CLIMATES

Students' attitudes and perceived purposes of physical education in Singapore: Perspectives from a 2x2 achievement goal framework. European Physical Education Review, 14, 51-70. DOI: $10.1177 / 1356336 X 07085709$

Wang, J. C. K., Liu, W. C., Chatzisarantis, N. L. D. \& Lim, C. B. S. (2010). Influence of perceived motivational climate on achievement goals in physical education: a structural equation mixture modeling analysis. Journal of Sport \& Exercise Psychology, 32(3), 324-338.

Weiner, I. B., Schinka, J. A., \& Velicer, W. F. (2012). Handbook of Psychology: Volume 2 - Research Methods in Psychology (2nd Edition). London: Wiley.

Weiss, M. R., Amorose, A. J., \& Wilko, A. M. (2009). Coaching behaviors, motivational climate, and psychosocial outcomes among female adolescent athletes. Pediatric Exercise Science, 21, 475492.

White, S. A. (1996). Goal orientation and perceptions of the motivational climate initiated by parents. Pediatric Exercise Science, 8, 122-129.

White, S. A., Kavussanu, M., \& Guest, S. M. (1998). Goal orientations and perceptions of motivational climate created by significant others. European Journal of Physical Education, 3, 212-228. DOI: 10.1080/1740898980030209.

Williams, L. (1998). Contextual influences and goal perspectives among female youth sport participants. Research Quarterly for Exercise and Sport, 69, 47-57.

Xiang, P., Bruene, A., \& McBride, R. E. (2004). Using achievement goal theory to assess an elementary physical education running program. Journal of School Health, 74, 220-225.

Xiang, P., \& Lee, A. (2002). Achievement goals, perceived motivational climate, and students' self reported mastery behaviours. Research Quarterly for Exercise and Sport, 73, 58-65.

Yoo, J. (1999). Motivational-behavioral correlates of goal orientation and perceived motivational climate in physical education. Perceptual and Motor Skills, 89, 262-274. 
INTRAPERSONAL CORRELATES OF MOTIVATIONAL CLIMATES

1 Zason, L. K., \& Wang, C. K. J. (2008). Motivational profiles of junior college athletes: A cluster analysis. Journal of Applied Sport Psychology, 20, 137-156. DOI:

$10.1080 / 10413200701805265$ 